\title{
Removal of rhodamine $B$ from aqueous solution by adsorption on corn cobs activated carbon
}

\author{
Kambiré Ollo ${ }^{1, *}$, Kouakou Yao Urbain ${ }^{1}$, Kouyaté Amadou ${ }^{2}$, Sadia Sahi Placide ${ }^{3}$, Kouadio Kouakou \\ Etienne $^{3}$, Kimou Kouakou Jocelin ${ }^{3}$ and Koné Souleymane ${ }^{3}$ \\ ${ }^{1}$ UFR Sciences et Technologies, Université de Man, BP 20 Man, Côte d'Ivoire. \\ ${ }^{2}$ UFR Environnement, Université Jean Lorougnon Guédé, BP 150 Daloa, Côte d'Ivoire. \\ ${ }^{3}$ Laboratoire de constitution et réaction de la matière, UFR SSMT, Université Félix Houphouët-Boigny de \\ Cocody, Abidjan, 22 BP 582 Abidjan 22, Côte d'Ivoire.
}

\begin{abstract}
In the present study, adsorption experiments were carried out to investigate the removal of rhodamine B from an aqueous solution using chemically activated carbon from corn cobs, a cheaper adsorbent. The characteristics of carbon were determined using X-ray diffraction, SEM, iodine number, pHpzc, and the Boehm titration method. The results show that the prepared activated carbon is amorphous, microporous, and generally acidic on the surface. The kinetic study of the adsorption of rhodamine B on this carbon was carried out, and the rate of sorption was found to conform to pseudo-second-order kinetics with $80 \mathrm{~min}$ as equilibrium time. The equilibrium adsorption revealed that the experimental data fitted better to the Langmuir isotherm model for removing rhodamine $\mathrm{B}$. The interaction rhodamine $\mathrm{B}$-activated carbon is mainly chemisorption type. The optimal conditions of rhodamine $\mathrm{B}$ removal onto the carbon of this study are mass of carbon $=0.3 \mathrm{~g}$ and $\mathrm{pH}=3.15$. The maximum monolayer adsorption capacity for rhodamine B removal was found to be $5.92 \mathrm{mg} . \mathrm{g}^{-1}$. This study has shown that the prepared activated carbon makes it possible to effectively clean up wastewater contaminated by rhodamine B with a removal efficiency of up to $99.60 \%$ for $300 \mathrm{mg}$ of AC in $25 \mathrm{~mL}$ of the rhodamine B solution $\left(5 \mathrm{mg} \cdot \mathrm{L}^{-1}\right)$.
\end{abstract}

Keywords: Corn cobs; activated carbon; adsorption; rhodamine B; Surface properties.

\section{Introduction}

Water, an essential component of ecosystems, plays a vital role in our daily life. However, we are now witnessing an increasing depletion of freshwater resources, mainly due to solid demographic growth and poor management of water resources ${ }^{1}$. Industrial activities put increased pressure on freshwater reserves through the pollutants they release. Industries as diverse as petrochemicals, food processing, textiles, stationery, tanneries etc., produce a wide variety of effluents that require new investigations and the development of specific processes ${ }^{2-5}$. Among the most polluting industries, we can cite the textile industry. The textile industry is considered an industrial sector that uses the most water and complex chemical compounds during manufacturing processes ${ }^{6}$. These industries pollute the environment enormously since more than $10 \%$ of the dyes used are found in the effluents ${ }^{7}$. However, even at low doses, dyes are likely to cause adverse effects on the environment ${ }^{8}$.
Therefore, it is necessary to treat these effluents before discharged into nature. To this end, various effluent treatment methods exist biological, chemical, electrochemical, and physical methods ${ }^{9-11}$.

Among these methods, adsorption techniques have successfully removed organic species ${ }^{12-16}$. Currently, activated carbon is the most commonly used adsorbent due to its adsorbing power, which is very important concerning dyes, but the downside is that commercial activated carbon is expensive. To this end, many studies relating to adsorption are directed towards the search for new effective and inexpensive adsorbents produced by agriculture waste material such as plantain peel, coconut shell, macadamia nut endocarp, and Palmae biomass ${ }^{17-20}$. Moreover, corn cobs are used to prepare activated carbon, and these carbons help remove metals and dye from waste water $^{21}$.

The objective of this study is to apply the adsorption process using activated carbon produced from corn 
cobs, a locally available precursor, abundant and inexpensive for the decontamination of water laden with rhodamine B (organic dye). The corn cobs were chosen because, in our country, they are thrown away after using the corn kernels. They are therefore free materials. However, very few authors have used activated carbon from corn cobs for water treatment in our country. Thus, the corn cob carbon will be activated by $\mathrm{H}_{3} \mathrm{PO}_{4}$; this allows an activated carbon with a large specific surface ${ }^{22}$.

Various experimental parameters will be analyzed, such as specific surface, the mass of adsorbent, $\mathrm{pH}$, contact time, initial concentration of rhodamine B, and temperature.

\section{Experimental}

\subsection{Preparation of activated carbon}

The preparation and activation of the carbon were carried out thermally and chemically using phosphoric acid at $500^{\circ} \mathrm{C}$. The corn cobs were crushed into small pieces, washed in tap water to remove dust, washed with distilled water, and dried in an oven at $105^{\circ} \mathrm{C}$ for $24 \mathrm{~h}$. After this step, the corn cobs were impregnated at room temperature and atmospheric pressure with magnetic stirring in a solution of $\mathrm{H}_{3} \mathrm{PO}_{4}$. The mass ratio $\left(\mathrm{H}_{3} \mathrm{PO}_{4}\right.$ : corn cobs $)$ is $1: 1$. The carbonaceous material is carbonized at $500^{\circ} \mathrm{C}$ for 4 hours in an OBERSAL brand oven ${ }^{22}$. The carbon obtained is washed thoroughly, after cooling, with distilled water until the $\mathrm{pH}$ of the rinsing water is between 6 and 7. The carbon obtained is dried in an oven at $105^{\circ} \mathrm{C}$ for $24 \mathrm{~h}$, then crushed and sieved (size $\leq 125 \mu \mathrm{m})$.

\subsection{Characterization of activated carbons}

The adsorption of acetic acid determined the specific surface area in an aqueous medium ${ }^{23}$. The iodine number was determined by adapting the CEFIC 1989 method and the standard AWWA B 600-90 ${ }^{24}$. To do this, $100 \mathrm{~mL}$ of $0.1 \mathrm{~N}$ iodine solution is treated hot and in an acidic medium for 30 seconds with a quantity of activated carbon. The treated solution is filtered, and $50 \mathrm{~mL}$ of the filtrate is titrated with $0.1 \mathrm{~N}$ sodium thiosulfate solution with starch as an indicator of the end of the reaction.

The surface functions were determined and quantified using the Boehm titration method by activating carbon on $\mathrm{NaHCO}_{3}, \mathrm{CaCO}_{3}, \mathrm{NaOH}$, and $\mathrm{HCl}^{25}$.

The determination of the pHpzc was carried out by adding $0.15 \mathrm{~g}$ of activated carbon (AC) to $50 \mathrm{~mL}$ of $\mathrm{NaCl}$ solutions $(0.01 \mathrm{M})$. The $\mathrm{pH}$ of each mixture is adjusted between 2 and 12 by adding $0.1 \mathrm{M} \mathrm{NaOH}$ or $\mathrm{HCl}$ solution. Stirring is maintained for 48 hours at a temperature of $25^{\circ} \mathrm{C}$. The final $\mathrm{pH}$ of each mixture is then measured. We draw the graph $\Delta \mathrm{pH}=\mathrm{f}(\mathrm{pHi})$. The $\mathrm{pHpzc}$ is the point of intersection of the curve with the axis that passes through zero.

The ash content of the carbon was determined by referring to the ASTM (American Standards Technology Method), ASTM D 2866-94 ${ }^{26}$. A mass of carbon is placed in a crucible and then placed in an oven at $650^{\circ} \mathrm{C}$ until there is no more detectable mass loss. This happens after $7 \mathrm{~h}$.

The morphology of activated carbon was determined by scanning electron microscope (SEM) using a Tescan LYRA 3 XMH.

The crystal structures were analyzed by an X-Ray diffractometer (D8 Advance Bruker, Germany) with a germanium detector for angle $2 \theta$ between $20-120^{\circ}$ with a scan rate of $0.01 \%$ s.

\subsection{Spectrophotometric determination of samples} Rhodamine $\mathrm{B}$ is a cationic dye of index CI-52015 with the formula $\mathrm{C}_{28} \mathrm{H}_{31} \mathrm{~N}_{2} \mathrm{O}_{3} \mathrm{Cl}$. It is used as a model molecule in the adsorption of dyes on activated carbon. The UV HACH DR 6000 spectrophotometer was used to determine the concentrations of rhodamine B on the solution. All information about rhodamine B is given in Table 1 and Figure 1.

Table 1. Properties of rhodamine B.

\begin{tabular}{|c|c|}
\hline Parameters & Values \\
\hline Suggested name & Rhodamine B \\
\hline C.I. number & 45170 \\
\hline C.I. name & Basic violet 10 \\
\hline Class & Rhodamine B \\
\hline$\lambda$ max & 554 nm \\
\hline Molecular formula & $\mathrm{C}_{28} \mathrm{H}_{31} \mathrm{~N}_{2} \mathrm{O}_{3} \mathrm{Cl}$ \\
\hline Formula weight & 479.02 \\
\hline
\end{tabular}


<smiles>CCN(CC)c1ccc2c(-c3ccccc3C(=O)O)c3ccc(=[N+](Cl)CC)cc-3oc2c1</smiles>

(a)<smiles>CCN(CC)c1ccc2c(-c3ccccc3C(=O)[O-])c3ccc(=[N+](CC)CC)cc-3oc2c1</smiles>

(b)

Figure 1. Structures of rhodamine B in its (a) cationic, and (b) zwitterionic forms

\subsection{Kinetic adsorption study}

The study of rhodamine B adsorption kinetics onto activated carbon was carried out at room temperature. The aim is to determine the time required to reach adsorption equilibrium and kinetic order. For the kinetic adsorption study, $100 \mathrm{mg}$ of activated carbon was mixed with $100 \mathrm{~mL}$ of $5 \mathrm{mg} . \mathrm{L}^{-1}$ of rhodamine B. These mixtures were shaken on a magnetic agitator at $150 \mathrm{rpm}$ for intervals of 5 and 120 minutes. After each contact time, solutions were filtered and the initial and final concentrations of rhodamine $\mathrm{B}$ were determined by spectrophotometer UV $\mathrm{HACH}$ DR 6000. The amount of rhodamine B adsorbed onto carbon is calculated according to the following equation:

$q_{t}=\frac{\left(C_{0}-C_{t}\right)}{m} x V$

Where $q_{t}$ is the amount of rhodamine B adsorbed by activated carbon $(\mathrm{mg} / \mathrm{g}) ; C_{0}$ and $C_{t}$ are respectively the initial and the final concentration of rhodamine $\mathrm{B}$ at a time after filtration $(\mathrm{mg} / \mathrm{L}) ; V$ is the initial solution volume (L); $m$ is the mass of the activated carbon $(\mathrm{g})$.

\subsection{Adsorption isotherms}

For equilibrium adsorption study, $300 \mathrm{mg}$ of activated carbon was mixed with $25 \mathrm{~mL}$ of different rhodamine B concentrations: $1 \mathrm{mg} . \mathrm{L}^{-1}, 2 \mathrm{mg} . \mathrm{L}^{-1}, 2.5 \mathrm{mg} . \mathrm{L}^{-1}$, $5 \mathrm{mg} . \mathrm{L}^{-1}$ and $10 \mathrm{mg} . \mathrm{L}^{-1}$. Then reaction mixtures were shaken on a magnetic agitator at $150 \mathrm{rpm}$ for equilibrium time $(80 \mathrm{~min})$ at room temperature. After equilibrium time, samples were filtered and spectrophotometer UV HACH DR 6000. The amount of rhodamine B adsorbed per unit mass of activated carbon at equilibrium, qe, was calculated by:

$\mathrm{q}_{\mathrm{e}}=\frac{\left(\mathrm{C}_{0}-\mathrm{C}_{\mathrm{e}}\right)}{\mathrm{m}} \times \mathrm{V}$

Where $\mathrm{C}_{0}$ and $\mathrm{C}_{\mathrm{e}}$ are the concentrations of rhodamine $\mathrm{B}$ at initial and equilibrium times, respectively; $\mathrm{V}$ is the volume of the $(\mathrm{L})$, and $\mathrm{m}$ is the mass of activated carbon used $(\mathrm{g})$.

\section{Results and discussion}

\subsection{Characterization of activated carbon}

The characteristics of activated carbon $(\mathrm{AC})$ are given in Table 2.

Table 2. Characteristics of activated carbon in this study.

\begin{tabular}{|c|c|}
\hline Parameters & Values \\
\hline Ash content & $6 \%$ \\
\hline Surface area $\left(\mathrm{m}^{2} \cdot \mathrm{g}^{-1}\right)$ & 613 \\
\hline Iode number $\left(\mathrm{mg} \cdot \mathrm{g}^{-1}\right)$ & 674 \\
\hline pHpzc & 5.3 \\
\hline Carboxyl $\left(\mathrm{mmol.g} \mathrm{g}^{-1}\right)$ & 1.48 \\
\hline Lactonic $\left(\mathrm{mmol} \cdot \mathrm{g}^{-1}\right)$ & 1.90 \\
\hline phenolic $\left(\mathrm{mmol} \cdot \mathrm{g}^{-1}\right)$ & 2.02 \\
\hline Acidic $\left(\mathrm{mmol} \cdot \mathrm{g}^{-1}\right)$ & 5.40 \\
\hline Basic $\left(\mathrm{mmol} . \mathrm{g}^{-1}\right)$ & 2.05 \\
\hline
\end{tabular}

The low ash content reflects a low fraction of mineral compounds and, therefore, good preparation of the carbon with a sizeable carbonaceous fraction ${ }^{27}$. The iodine number gives an estimate of the relative area of the sample and is generally used to measure the porosity of pores larger than $1.0 \mathrm{~nm}$ in diameter. In this study, the iodine number is $674 \mathrm{mg} / \mathrm{g}$. This result is in the typical range of 500 to $1200 \mathrm{mg} / \mathrm{g}$, reflecting the porous character of this carbon ${ }^{22}$. So, this activated carbon could be excellent in the adsorption of molecules in the liquid phase ${ }^{28,29}$. The $\mathrm{pH}$ of zero charges (pHpzc) of carbon, the point at which the net 
charge of adsorbent is zero, was measured using the acid/base titration method. The pHpzc was found to be 5.3. The carbon has a generally acidic surface dominated by the phenolic, lactonic, and carboxylic functions. Vargas et al. obtained activated carbons based on flamboyant pods with similar surface functions ${ }^{30}$. Surface areas were measured using the adsorbed acetic acid method. The value of the specific surface of the prepared carbon is $613 \mathrm{~m}^{2} / \mathrm{g}$.
This value is greater than the specific surface area of activated carbons produced with Solid olive waste by Hamouz et al. ${ }^{23}$.

The X-ray diffraction (XRD) pattern of the Activated is illustrated in Figure 2. The appearance of broad diffraction background and the absence of a sharp peak reveals a predominantly amorphous structure ${ }^{31}$.

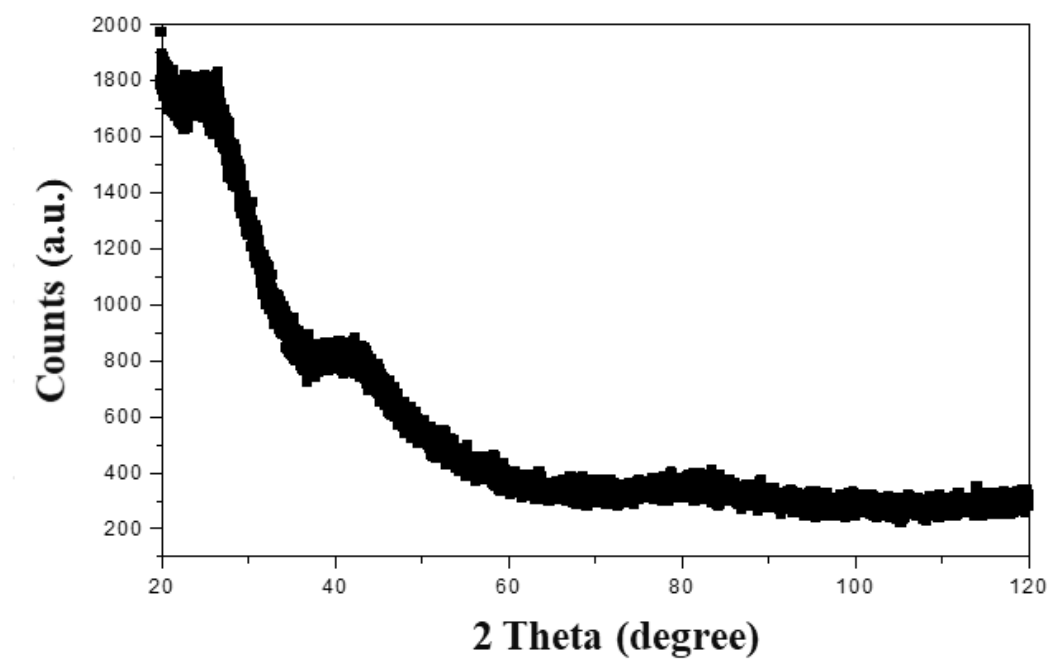

Figure 2. The X-ray diffraction pattern of corn cobs activated carbon

\subsection{Scanning electron micrographs (SEM) analysis}

The SEM images of activated carbon from corn cobs before and after adsorption of rhodamine B are shown in Figure 3. The magnification scale of the SEM is 3000. The SEM image of activated carbon (Figure 3a) shows open and irregular pores on the surface of the carbon. These pores express the activation of carbon

\section{(a)}

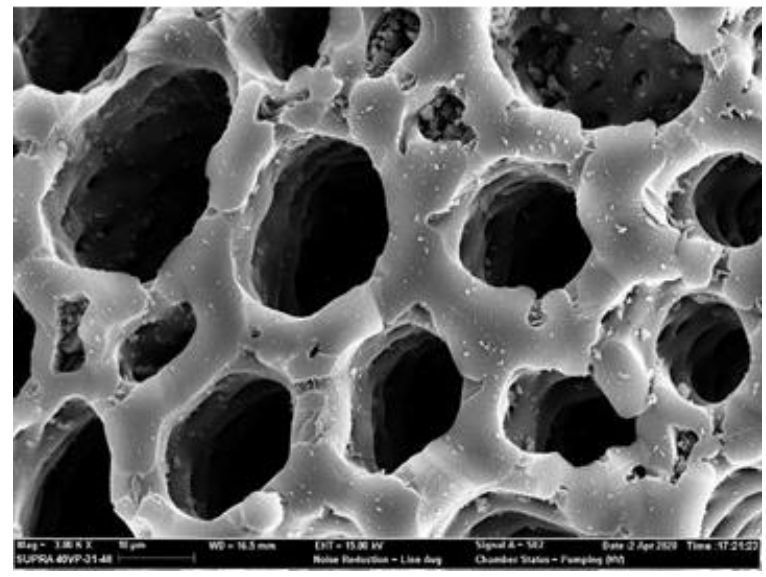

Figure 3. SEM image of activated carbon (a) and after adsorption of rhodamine B (b)

\subsection{Effect of contact time on adsorption}

The effect of contact time on adsorption was studied by contacting $5 \mathrm{mg} \mathrm{L}^{-1}$ of rhodamine B with $100 \mathrm{mg}$ of activated carbon in $100 \mathrm{~mL}$. The results obtained are recorded in Figure 4. This figure notes an increase in the adsorption rate with up to 80 minutes of contact time. After 80 minutes, the adsorption rate remains and its microporous appearance. RB molecules entered the pores after adsorption of rhodamine B (Figure $3 \mathrm{~b}$ ). In addition, there are some hollows on the surface of the carbon. This is because the rhodamine $\mathrm{B}$, after filling the pores, is bound to the surface of the carbon, giving an almost smooth surface. There was, therefore, a strong interaction between rhodamine B and activated carbon.

\section{(b)}

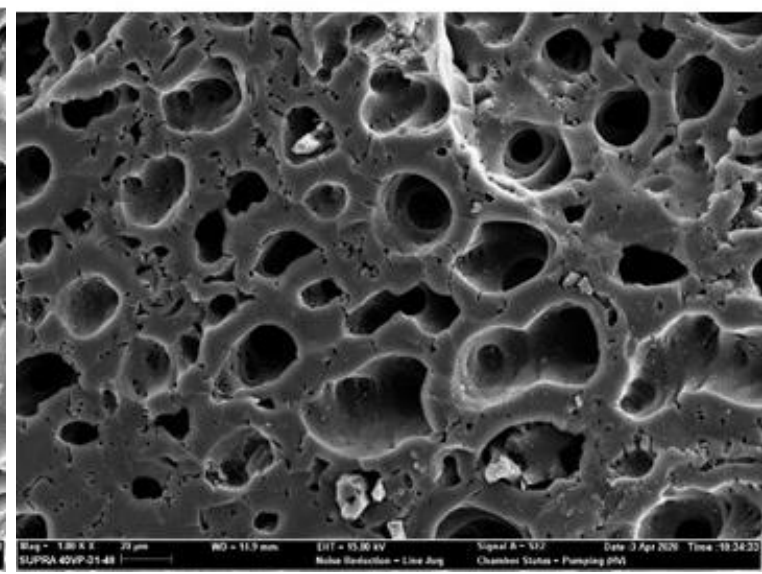

constant, despite increasing time (Figure 4). The increase in adsorption capacity as a function of contact time is due to the availability of adsorption sites as soon as adsorption begins. The level obtained indicates the saturation of the available adsorption sites. This achieves the activated carbon's ultimate adsorption capacity (qm) after 80 minutes. 


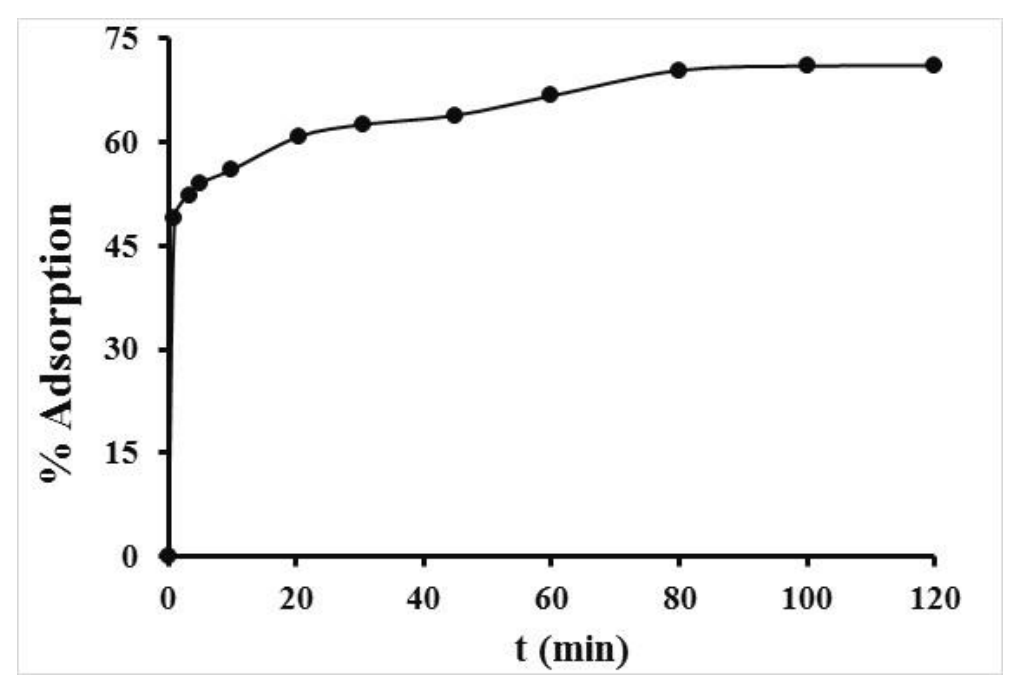

Figure 4. Removal efficiency of rhodamine B $\left(5 \mathrm{mg} \cdot \mathrm{L}^{-1}\right)$ on activated carbon; mass of activated carbon $=100 \mathrm{mg}$ in $100 \mathrm{~mL} ; \mathrm{pH}=6.16 ; \mathrm{T}=25^{\circ} \mathrm{C}$

\subsection{Kinetics of adsorption}

In order to determine which kinetic model best describes the adsorption of rhodamine $\mathrm{B}$ on activated carbon, the pseudo-first-order and pseudo-secondorder models were applied, using equations 3 and $4^{32,33}$.

$\ln \left(q_{e}-q_{t}\right)=\ln q_{e}-k_{1} t$

$\frac{\mathrm{t}}{\mathrm{q}_{\mathrm{t}}}=\frac{1}{\mathrm{k}_{2} \mathrm{qe}^{2}}+\frac{1}{q_{e}} t$

Where $\mathrm{q}_{\mathrm{e}}$ and $\mathrm{q}_{\mathrm{t}}$ are, respectively, the amounts of rhodamine $\mathrm{B}$ adsorbed per mass of activated carbon at equilibrium and at time $\mathrm{t}$ in $\left(\mathrm{mg} \cdot \mathrm{g}^{-1}\right) ; \mathrm{k}_{1}(1 / \mathrm{h})$ and $\mathrm{k}_{2}$ $\left(\mathrm{g} \cdot \mathrm{mg}^{-1} \cdot \mathrm{h}^{-1}\right)$ the adsorption rate constants.

The plotted curves are respectively ln (qe - qt) as a function of time and $t / q_{t}$ as a function of time. The results obtained are presented in Figures $5 \mathrm{a}$ and $5 \mathrm{~b}$. The kinetic parameters of the pseudo-first-order and pseudo-second-order surface reactions are given in
Table 3. The determination coefficient (0.997) obtained with the pseudo-second-order model is higher than that obtained (0.978) for pseudo-firstorder, indicating that the pseudo-second-order kinetic model is better suited to describe the adsorption of rhodamine $\mathrm{B}$ onto activated carbon ${ }^{34}$. The theoretical maximum amount of rhodamine $\mathrm{B}$ adsorbed per mass of carbon $\left(\mathrm{q}_{\mathrm{e}}\right)$ at equilibrium gave a value of $0.871 \mathrm{mg} \cdot \mathrm{g}^{-1}$. The maximum experimental values of the amount of rhodamine $\mathrm{B}$ adsorbed were also determined. The values of 0.337 and $0.866 \mathrm{mg} \cdot \mathrm{g}^{-1}$ were obtained respectively for the pseudo-first-order and the pseudo-order 2 models. These values show that the experimental value $\left(0.866 \mathrm{mg} . \mathrm{g}^{-1}\right)$ of the maximum quantity of rhodamine $\mathrm{B}$ adsorbed is close to the theoretical value $\left(0.871 \mathrm{mg} \cdot \mathrm{g}^{-1}\right)$ obtained by applying the pseudo-second-order kinetic model. This confirms that the pseudo-second-order kinetic model is suitable for our study.
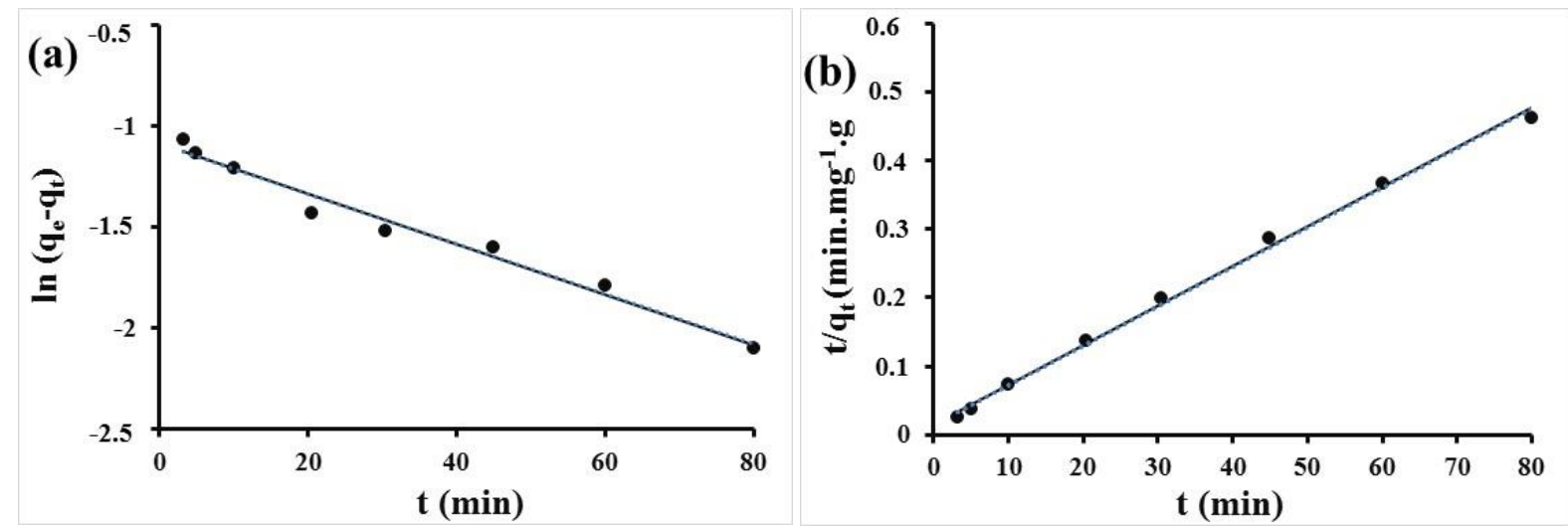

Figure 5. Pseudo-first-order (a) and pseudo-second-order (b) kinetic models of adsorption of rhodamine B 
Table 3. Kinetic parameters of RB adsorption on activated carbon.

\begin{tabular}{|c|c|c|}
\hline \multirow{2}{*}{ Pseudo-first order } & $\mathrm{k}_{1}\left(\mathrm{~min}^{-1}\right)$ & 0.013 \\
\cline { 2 - 3 } & $\mathrm{R}^{2}$ & 0.978 \\
\cline { 2 - 3 } & $\mathrm{q}_{\mathrm{e} . \mathrm{cal}}\left(\mathrm{mg} \cdot \mathrm{g}^{-1}\right)$ & 0.337 \\
\hline \multirow{2}{*}{ Pseudo-second order } & $\mathrm{q}_{\mathrm{e} . \mathrm{exp}}\left(\mathrm{mg} \cdot \mathrm{g}^{-1}\right)$ & 0.871 \\
\hline & $\mathrm{k}\left(\mathrm{g} \cdot \mathrm{m}^{-1} \cdot \mathrm{min}^{-1}\right)$ & 1.214 \\
\hline & $\mathrm{R}^{2}$ & 0.997 \\
\hline & $\mathrm{q}_{\mathrm{e} . \mathrm{cal}}\left(\mathrm{mg} \cdot \mathrm{g}^{-1}\right)$ & 0.866 \\
\hline
\end{tabular}

\subsection{Rhodamine $B$ adsorption isotherms}

The data on the adsorption of rhodamine $\mathrm{B}$ on activated carbon are processed according to the linear equations of Langmuir and Freundlich. This linearization aims to verify the model according to which the adsorption takes place and deduce from it the maximum adsorbed quantities and the adsorbate affinity for the adsorbent.

The linear form of the Langmuir isotherm is given by the following equations ${ }^{13,35}$.

$\frac{C_{e}}{q_{e}}=\frac{C_{e}}{q_{m}}+\frac{1}{q_{m}} b$

Where constants $b$ and $q_{m}$ are related to the energy of adsorption and adsorption capacity, their values are obtained from the slope and intercept of the plot of $\mathrm{Ce} / \mathrm{q}_{\mathrm{e}}$ versus $\mathrm{Ce}$ as shown in Figure 6, and Table 4.

The adsorption data obtained are also fitted to the Freundlich isotherm, the earliest known relationship described by equation ${ }^{13,36}$.

$\log q_{e}=\log K_{f}+\frac{1}{n} \log C_{e}$

$\mathrm{K}_{\mathrm{f}}$ and $\mathrm{n}$ were Freundlich constants, corresponding to adsorption capacity and adsorption intensity, respectively. The slope $(1 / \mathrm{n})$ and intercept $\left(\mathrm{K}_{\mathrm{f}}\right)$ of $\log$ $\mathrm{q}_{\mathrm{e}} \mathrm{vs} \log \mathrm{Ce}$ are determined. The results of both regressed isotherms are tabulated in Figure 6 and Table 4.



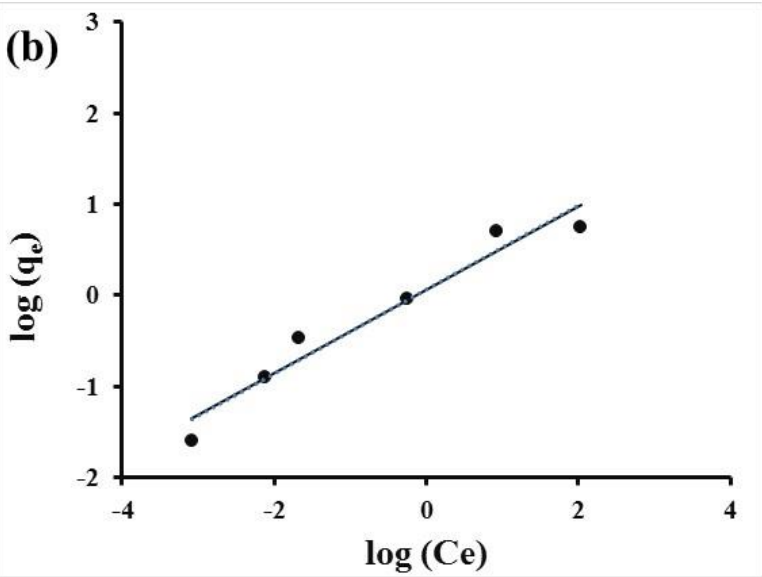

Figure 6. (a) Langmuir isotherm plots for the adsorption of RB and (b) Freundlich isotherm plots for the adsorption of RB

In the case of the Freundlich model, the possibility of the model being applied depends on the values $n$. Thus for $2<\mathrm{n}<10$, the adsorption is better; when $1<\mathrm{n}<2$, the adsorption is favorable, and for $\mathrm{n}<1$, it is almost difficult for the molecule to adsorb ${ }^{37}$. According to Table 4, the value of $n$ is equal to 2.17 . This value is between 2 and 10; this shows that the adsorption is better according to the Freundlich model. Thus the Freundlich model is applicable. However, the model that best describes this adsorption is Langmuir, where the linear determination coefficient $\left(\mathrm{R}^{2}=0.99\right)$ is higher than that of the Freundlich model $\left(\mathrm{R}^{2}=0.94\right)$. This table also shows that the maximum adsorption capacity of rhodamine B is $5.92 \mathrm{mg} \cdot \mathrm{g}^{-1}$. 
Table 4. Rhodamine B adsorption isotherms parameter values.

\begin{tabular}{|c|c|c|c|c|c|}
\hline \multicolumn{3}{|c|}{ Langmuir } & \multicolumn{3}{c|}{ Freundlich } \\
\hline $\mathrm{R}^{2}$ & $q_{m}\left(\mathrm{mg} \cdot \mathrm{g}^{-1}\right)$ & $\mathrm{b}$ & $\mathrm{R}^{2}$ & $\mathrm{~K}_{\mathrm{f}}$ & $\mathrm{n}$ \\
\hline 0.99 & 5.92 & 0.59 & 0.94 & 1.06 & 2.17 \\
\hline
\end{tabular}

The maximum monolayer adsorption capacity $\left(\mathrm{q}_{\max }\right)$ values obtained for the adsorption of $\mathrm{RhB}$ onto corn cobs activated carbon in our study were compared with those obtained by using other adsorbents (Table 5). The amount of rhodamine B adsorbed on our carbon is greater than coal and in the same order as the other adsorbents in the table.

Table 5. Adsorption capacities of Rhodamine B on various adsorbents.

\begin{tabular}{|c|c|c|}
\hline Adsorbent & Maximum adsorbent capacity, $q_{\text {max }}\left(\mathrm{mg}_{\mathrm{g}} \mathrm{g}^{-1}\right)$ & References \\
\hline Tamarind fruit shells activated carbon & 3.94 & 38 \\
\hline Coal & 1.24 & 39 \\
\hline Acid activated mango leaf powder & 3.31 & 40 \\
\hline Fly ash & 2.33 & This study \\
\hline
\end{tabular}

\subsection{Mass Effect of activated carbon}

To determine the optimum mass necessary to remove rhodamine B, $25 \mathrm{~mL}$ of the rhodamine B solution (5 mg. $\mathrm{L}^{-1}$ ) contact different activated carbon masses. The results obtained are shown in Figure 7. This figure shows an increase in the adsorption percentage with the mass of the activated carbon. The adsorption percentage thus goes from $36.71 \%$ to $96.84 \%$, when the mass of the activated carbon goes from 25 to 200 $\mathrm{mg}$. The adsorption rate increases to $99.60 \%$ for 300 $\mathrm{mg}$. From $300 \mathrm{mg}$, the adsorption percentage remains practically constant up to $600 \mathrm{mg}$. The increase in the ratio of adsorbent observed as a function of the mass of the activated carbon is due to the availability of free adsorption sites, which increases with the amount of adsorbent up to mass $300 \mathrm{mg}$. At low doses of activated carbon, the dye readily accesses the sites of adsorbed carbon, whereby the amount adsorbed rapidly increases with the mass of the activated carbon ${ }^{42-44}$. However, in order to save AC, a mass of $200 \mathrm{mg}$ will be used for further work.

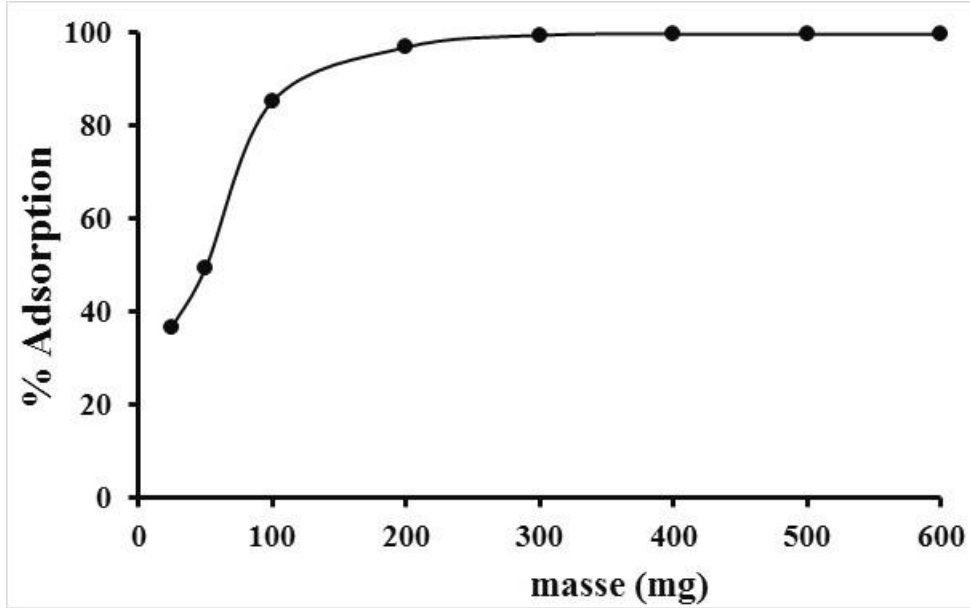

Figure 7. Influence of the mass of adsorbent on the adsorption of rhodamine $\mathrm{B} ; \mathrm{pH}=6.16 ; \mathrm{T}=25^{\circ} \mathrm{C}$

\subsection{Effect of initial pH on adsorption}

The $\mathrm{pH}$ of the solution strongly influences the adsorption of the organic compound on activated carbon. The nature of the adsorbate in solution and the load on the surface of the adsorbent depends on the $\mathrm{pH}$. The effect of the $\mathrm{pH}$ of the solution on $\mathrm{RB}$ adsorption on the prepared activated carbon was studied in the $\mathrm{pH}$ range of 2 to 10.1 , using a mass of $200 \mathrm{mg}$ of activated carbon in $25 \mathrm{~mL}$. The results are presented in Figure 8. This figure shows that the maximum adsorption was recorded at $\mathrm{pH} 3.15$, where the $\mathrm{RB}$ absorption is $98.92 \%$, while the minimum adsorption is observed at $\mathrm{pH} 10$.

The high removal efficiency at $\mathrm{pH} 3.15$ can be attributed to the change like $\mathrm{RB}$ depending on the $\mathrm{pH}$ of the solution. The difference in $\mathrm{pH}$ results in the formation of different ionic species, and of notable importance is the zwitterionic form (Figure 1b) which 
occurs at $\mathrm{pH}>3.7(\mathrm{pKa}=3.7)$. At $\mathrm{pH}>3.7$, the attractions between the carboxyl and xanthene of the $\mathrm{RB}$ monomer groups result in the formation of $\mathrm{RB}$ dimers. Therefore, the absorption of RB becomes difficult, which decreases the adsorption capacity of the rhodamine $\mathrm{B}^{45}$. The maximum adsorption of $\mathrm{RB}$ at a $\mathrm{pH}$ between 3 and 4 has already been obtained in the literature ${ }^{45-47}$.



Figure 8. Effect of initial pH on RB adsorption

\subsection{Thermodynamic parameters}

The thermodynamic parameters of the adsorption reaction of rhodamine $\mathrm{B}$ on activated carbon, namely standard free energy $\left(\Delta \mathrm{G}^{\circ}\right)$, standard enthalpy $\left(\Delta \mathrm{H}^{\circ}\right)$ and standard entropy $\left(\Delta S^{\circ}\right)$ were determined from equations (7), (8) and (9) ${ }^{48}$ :

$\Delta G^{0}=\Delta H^{0}-T \Delta S$

$\ln K_{d}=\frac{\Delta S^{0}}{R}-\frac{\Delta H^{0}}{R T}$

$K_{d}=\frac{q_{e}}{C_{e}}$

Where $K_{d}$ is the distribution coefficient.

The curve $\ln K_{d}$ as a function of $1 / T$ has been illustrated in Figure 9.
The thermodynamic parameters obtained are given in Table 6. The analysis of these thermodynamic parameters shows that the $\mathrm{RB}$ adsorption on the activated carbon is a spontaneous reaction because, whatever the temperature, the value of the standard free enthalpy variation $\left(\Delta G^{\circ}\right)$ is negative ${ }^{10,49}$. The interpretation of the typical free energy changes inversely with the temperature of the solution. Thus, increasing the temperature further promotes the absorption process of $\mathrm{RB}$ on the activated carbon. The positive sign of the standard enthalpy $\left(\Delta \mathrm{H}^{\circ}\right)$ shows that the adsorption process is endothermic. The standard enthalpy value is less than $40 \mathrm{~kJ} \mathrm{~mol}^{-1}$. This indicates that it is a physisorption ${ }^{50,51}$. The positive sign of entropy $\left(\Delta S^{\circ}\right)$ indicates the disorder of RB molecules at the solid-solution interface during the adsorption process 52,53 .

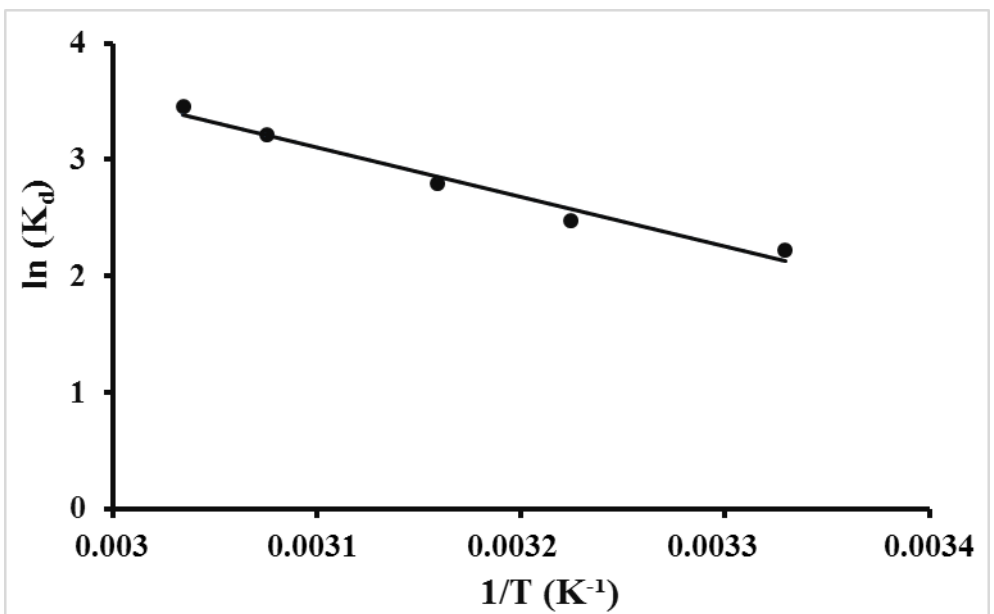

Figure 9. $\mathrm{Ln}(\mathrm{Kd})$ versus 1 / T curve for the adsorption of rhodamine B on activated carbon 
Table 6. Thermodynamic parameters.

\begin{tabular}{|c|c|c|c|c|c|}
\hline$\Delta \mathbf{H}^{\circ}\left({\mathrm{J} . \mathrm{mol}^{-1}}^{-1}\right)$ & \multicolumn{5}{|c|}{35345.31} \\
\hline$\Delta \mathbf{S}^{\circ}\left(\mathrm{J} \mathrm{mol}^{-1} \cdot \mathbf{K}^{-1}\right)$ & \multicolumn{5}{|c|}{135.40} \\
\hline \multirow{2}{*}{$\Delta \mathbf{G}^{\circ}\left(\mathrm{J} \mathrm{mol}^{-1}\right)$} & $300.35 \mathrm{~K}$ & $310.15 \mathrm{~K}$ & $316.55 \mathrm{~K}$ & $325.15 \mathrm{~K}$ & $329.55 \mathrm{~K}$ \\
\hline & -5322.08 & -6651.00 & -7515.56 & -8680.00 & -9275.76 \\
\hline
\end{tabular}

\section{Conclusion}

The equilibrium, kinetics, and thermodynamics for the uptake of Rhodamine B dye by corn cobs activated carbon from aqueous solution were studied. The kinetic study of the RB adsorption on activated carbon showed that the adsorption rate of RB conforms to pseudo-second-order kinetics with $80 \mathrm{~min}$ as equilibrium time. The adsorption under investigation revealed that the experimental data fit the Langmuir isothermal model better. The maximum single-layer adsorption capacity to remove $\mathrm{RB}$ was found to be $5.92 \mathrm{mg} \mathrm{g}^{-1}$. The study of the influence of the $\mathrm{pH}$ of the initial solution showed that the absorption rate of $\mathrm{RB}$ is used at $\mathrm{pH}=3.15$. The analysis of the thermodynamic parameters showed that the adsorption process is physisorption, spontaneous and endothermic. This study has shown that the prepared activated carbon makes it possible to effectively clean up wastewater contaminated by rhodamine B with a removal efficiency of up to $99.60 \%$. This study has shown that the prepared activated carbon effectively removes wastewater contaminated with rhodamine $\mathrm{B}$ with an elimination efficiency of up to $99.60 \%$ for $300 \mathrm{mg}$ of $\mathrm{AC}$ in $25 \mathrm{~mL}$ of the rhodamine $\mathrm{B}$ solution $\left(5 \mathrm{mg} . \mathrm{L}^{-1}\right)$.

\section{Conflicts of Interest}

The authors declare no conflicts of interest

\section{References}

1- R.J. Wyman, The Effects of Population on the Depletion of Fresh Water, Population and Development Review, 2013, 39, 687-704.

2- R. Kaur, H. Kaur, Solar Driven Photocatalysis-an Efficient Method for Removal of Pesticides from Water and Wastewater, Biointerface Research in Applied Chemistry, 2021, 11, 9071-9084.

3- C. Tangsathitkulchai, S. Naksusuk, A. Wongkoblap, P. Phadungbut, P. Borisut, Equilibrium and Kinetics of $\mathrm{CO}_{2}$ Adsorption by Coconut Shell Activated Carbon Impregnated with Sodium Hydroxide, Processes, 2021, 9, 201.

4- T.J. Al-Musawi, A.H. Mahvi, A.D. Khatibi, D. Balarak, Effective adsorption of ciprofloxacin antibiotic using powdered activated carbon magnetized by iron(III) oxide magnetic nanoparticles, Journal Porous Materials, 2021, $28,835-852$.

5- O. Kambiré, L.A.G. Pohan, S.P. Sadia, K.E. Kouadio, L. Ouattara, Voltammetric study of formic acid oxidation via active chlorine on
$\mathrm{IrO}_{2} / \mathrm{Ti}$ and $\mathrm{RuO}_{2} / \mathrm{Ti}$ electrodes, Mediterranean Journal of Chemistry, 2020, 10, 799-808.

6- A.K. Verma, R.R. Dash, P. Bhunia, A review on chemical coagulation/flocculation technologies for removal of colour from textile wastewaters, Journal Environmental Management, 2012, 93, 154-168.

7- X. Liu, J. Luo, Y. Zhu, Y. Yang, S. Yang, Removal of methylene blue from aqueous solutions by an adsorbent based on metal-organic framework and polyoxometalate, Journal of Alloys and Compounds, 2015, 648, 986-993.

8- H.B. Mansour, O. Boughzala, D. Dridi, D. Barillier, L. Chekir-Ghedira, R. Mosrati, Textiles dyes as a source of wastewater contamination: screening of the toxicity and treatment methods, Revue des Sciences de l'Eau, 2011, 24, 209-238.

9- K.E. Kouadio, O. Kambiré, K.S. Koffi, L. Ouattara, Electrochemical oxidation of paracetamol on boron-doped diamond electrode: analytical performance and paracetamol degradation, Journal of Electrochemical Science and Engineering, 2021, 11, 71-86.

10- B. Coulibaly, L.A.G. Pohan, O. Kambiré, L.P.S. Kouakou, H. Goure-Doubi, D. Diabaté, L. Ouattara, Valorization of Green Clay from Bouaflé (Ivory Coast) in the Simultaneous Elimination of Organic Pollutants and Metallic Trace Elements by Adsorption: Case of Methylene Blue and Cadmium Ions, Chemical Science International Journal, 2020, 29, 37-51.

11-S.P. Sadia, O. Kambiré, C.Q-M Gnamba, L.A.G. Pohan, M. Berté, L. Ouattara, Mineralization of Wastewater from the Teaching Hospital of Treichville by a Combination of Biological Treatment and Advanced Oxidation Processes, Asian Journal of Chemical Sciences, 2021, 10, $1-10$.

12-S. Singh, A. Kumar, H. Gupta, Activated banana peel carbon: a potential adsorbent for Rhodamine B decontamination from aqueous system, Applied Water Science, 2020, 10, 185.

13-M. Abdallah, A. Hijazi, M. Hamieh, M. Alameh, J. Toufaily, H. Ramma, Treatment of industrial wastewater using a natural and biodegradable adsorbent based on Eucalyptus, Journal of Materials and Environmental Science, 2016, 7, 4036-4048.

14-K.M. Kifuani, A.K.K. Mayeko, P.N. Vesituluta, B.I. Lopaka, G.E. Bakambo, B.M. Mavinga, J.M. Lunguya, Adsorption d'un colorant basique, Bleu de Méthylène, en solution aqueuse, sur un 
bioadsorbant issu de déchets agricoles de Cucumeropsis mannii Naudin, International Journal of Biological and Chemical Sciences, 2018, 12, 558-575.

15-G.O. El-Sayed, M.M. Yehia, A.A. Asaad, Assessment of activated carbon prepared from corncob by chemical activation with phosphoric acid, Water Resources and Industry, 2014, 7-8, 66-75.

16-N.V. Sych, S.I. Trofymenko, O.I. Poddubnaya, M.M. Tsyba, V.I. Sapsay, D.O. Klymchuk, A.M. Puziy, Porous structure and surface chemistry of phosphoric acid activated carbon from corncob, Applied Surface Science, 2012, 261, 75-82.

17-V.E. Efeovbokhan, E.E. Alagbe, B. Odika, R. Babalola, T.E. Oladimeji, O.G. Abatan, E.O. Yusuf, Preparation and characterization of activated carbon from plantain peel and coconut shell using biological activators, Journal of Physics: Conference Series, 2019, 1378, 032035.

18-O.P. Junior, A.L. Cazetta, R.C. Gomes, É.O. Barizão, I.P.A.F. Souza, A.C. Martins, T. Asefa, V.C. Almeida, Synthesis of $\mathrm{ZnCl}_{2}$-activated carbon from macadamia nut endocarp (Macadamia integrifolia) by microwave-assisted pyrolysis: Optimization using RSM and methylene blue adsorption, Journal of Analytical and Applied Pyrolysis, 2014, 105, 166-176.

19-X. Xing, W. Jiang, S. Li, X. Zhang, W. Wang, Preparation and analysis of straw activated carbon synergetic catalyzed by $\mathrm{ZnCl}_{2}$ $\mathrm{H}_{3} \mathrm{PO}_{4}$ through hydrothermal carbonization combined with ultrasonic assisted immersion pyrolysis, Waste Management, 2019, 89, 64-72.

20-D. Egirani, M.T. Latif, N. Wessey, N.R. Poyi, N. Shehata, Preparation and characterization of powdered and granular activated carbon from Palmae biomass for mercury removal, Applied Water Science, 2011, 11, 10.

21-E.B. Nohier, K.E.E. Hisham, M. Hani, Highperformance removal of iron from aqueous solution using modified activated carbon prepared from corn cobs and luffa sponge, Desalination and Water Treatment, 2021, 213, 348-357.

22-E.A. Abo, Y.A. Yobouet, Y.U. Kouakou, A. Trokourey, Optimisation de la préparation de charbons activés à base d'épis de maïs et caractérisation physico-chimique, International Journal of Innovation and Applied Studies, 2020, 29, 1161-1171.

23-A.E. Hamouz, H.S. Hilal, N. Nashaat, M. Zahi, Solid olive waste in environmental cleanup: oil recovery and carbon production for water purification, Journal of Environmental Management, 2007, 84, 83-92.

24-CEFIC (Conseil européen de l'industrie chimique), Méthodes de contrôle et d'évaluation des charbons actifs, 1989.

25-H.P. Boehm, Some aspects of the surface chemistry of carbon blacks and other carbons, Carbon, 1994, 32, 759-769.
26-ASTM D2866-94, Standard Test Method for Total Ash Content of Activated Carbon, 1999.

27-Y.U. Kouakou, K.F. Essy, A. Dembélé, Y.S. Brou, S.A. Ello, B.I.M. Gouli, A. Trokourey, Removal of imidacloprid using activated carbon produced from ricinodendron heudelotii shells, Bulletin of Chemical Society of Ethiopia, 2017, 31, 397-409.

28-A.C. Ayhan, S. Ömer, O.B. Ahinb, S. Cafér, Surface and porous characterization of activated carbon prepared from pyrolysis of biomass by two-stage procedure at low activation temperature and it's the adsorption of iodine, Journal of Analytical and Applied Pyrolysis, 2013, 104, 378-383.

29-M. Lingeswarran, A. Farook, R.M. Abdul, N. Eng-Poh, The synthesis and characterization of high purity mixed microporous/mesoporous activated carbon from rice husk using chemical activation with $\mathrm{NaOH}$ and $\mathrm{KOH}$, Microporous and Mesoporous Materials, 2014, 197, 316-323.

30-A.M.M. Vargas, A.L. Cazetta, C.A. Garcia, J.C.G. Moraes, E.M. Nogami, E. Lenzi, W.F. Costa, V.C. Almeida, Preparation and characterization of activated carbon from a new raw lignocellulosic material: Flamboyant (Delonix regia) pods, Journal of Environmental Management, 2011, 92, 178-184.

31-M.S. Shamsuddina, N.R.N. Yusoffa, M.A. Sulaiman, Synthesis and Characterization of Activated Carbon Produced from Kenaf Core Fiber Using $\mathrm{H}_{3} \mathrm{PO}_{4}$ Activation, Procedia Chemistry, 2016, 19, 558-565.

32-S. Lagergren, Zur Theorie der Sogenannten Adsorption Gelöster Stoffe, Kungliga Svenska Vetenskapsakademiens, Handlingar, 1898, 24, $1-39$.

33-W. Plazinski, J. Dziuba, W. Rudzinski, Modeling of sorption kinetics: the pseudo-second-order equation and the sorbate intraparticle diffusivity, adsorption, 2013, 19, 1055-1064.

34-Y.S. HO, removal of copper ions from aqueous solution by tree fern, Water Resources, 2003, 37, 2323-2330.

35-N. Barka, K. Ouzaouit, M. Abdennouri, M. Makhfouk, Dried prickly pear cactus (Opuntia ficus indica) cladodes as a low-cost and ecofriendly biosorbent for dyes removal from aqueous solutions, Journal of the Taiwan Institute of Chemical Engineers, 2013, 44, 52-60.

36-W.J. Weber, J.C. Morris, Kinetics of Adsorption on Carbon from Solution, American Society of Civil Engineers, 1963, 89, 31-60.

37-O. Hamdaoui, E. Naffrechoux, Modeling of adsorption isotherms of phenol and chlorophenols onto granular activated carbon: Part I. Two-parameter models and equations allowing determination of thermodynamic parameters, Journal of Hazardous Materials, 2007, 147, 381-94.

38-A.E. Vasu, Studies on the removal of rhodamine $\mathrm{b}$ and malachite green from aqueous solutions by 
Tamarind fruit shells activated carbon, European Journal of Chemistry, 2008, 5, 844-852.

39-T.A. Khan, V. Singh, D. Kumar Removal of some basic dyes from artificial textile wastewater by adsorption on Akash kinari coal, Journal of Scientific and Industrial Research, 2004, 63, 355-364.

40-T.A. Khan, S. Sharma, I. Ali, Adsorption of Rhodamine B dye from aqueous solution onto acid activated mango (Magnifera indica) leaf powder: Equilibrium, kinetic and thermodynamic studies, Journal of Toxicology and Environmental Health Sciences, 2011, 3, 286-297.

41-T.A. Khan, I. Ali, V.V. Singh, S. Sharma, Utilization of fly ash as low-cost adsorbent for the removal of methylene blue, malachite green, and rhodamine B dyes from textile wastewater, Journal of Environmental Protection Sciences, 2009, 3, 11-22.

42-S. Arivoli, M. Thenkuzhali, P.M.D. Prasath, Adsorption of rhodamine B by acid-activated Carbon-Kinetic, thermodynamic and equilibrium studies, Orbital, 2009, 1, 138-155.

43-C. Namasivayam, N. Muniasamy, K. Gayatri, M. Rani, K. Ranganathan, Removal of dyes from aqueous solutions by cellulosic waste orange peel, Bioresource Technology, 1996, 57, 37-43.

44-C. Namasivayam, R.T. Yamuna, Adsorption of direct red 12 B by biogas residual slurry: Equilibrium and rate processes, Environmental Pollution, 1995, 89, 1-7.

45-A.A. Inyinbor, F.A. Adekola, G.A. Olatunji, Adsorption of Rhodamine B Dye from Aqueous Solution on Irvingia gabonensis Biomass: Kinetics and Thermodynamics Studies, South African Journal of Chemistry, 2015, 68, 115-125.
46-M. Zamouche, O. Hamdaoui, Sorption of Rhodamine B by Cedar Cone: Effect of $\mathrm{Ph}$ and Ionic Strength, Energy Procedia, 2012, 18, 1228-1239.

47-P.P. Gan, S.F.Y. Li, Efficient removal of Rhodamine B using a rice hull-based silicasupported iron catalyst by Fenton-like process, Chemical Engineering Journal, 2013, 229, 351-363.

48-E. Rubin, P. Rodriguez, R. Herrero, E.S. De Vicente, Adsorption of Methylene Blue on Chemically Modified Algal Biomass: Equilibrium, Dynamic, and Surface Data, Journal of Chemical and Engineering Data, 2010, 55, 5707-5714.

49-Y. Lei, L. Yong-ming, The adsorption mechanism of anionic and cationic dyes by Jerusalem artichoke stalk-based mesoporous activated carbon, Journal of Environmental Chemical Engineering, 2014, 2, 220-229.

50-R. Ahmad, R. Kumar, Adsorptive removal of congo red dye from aqueous solution using bael shell carbon, Appl. Surf. Sci., 2010, 257, 1628-1633.

51-Z.Y. Zhang, I.M. O’Hara, G.A. Kent, W.O.S. Doherty, Comparative study on adsorption of two cationic dyes by milled sugarcane bagasse, Industrial Crops, and Products, 2013, 42, 41-49.

52-F. Çolak, N. Atar, A. Olgun, Biosorption of acidic dyes from aqueous solution by Paenibacillus macerans: Kinetic, thermodynamic and equilibrium studies, Chemical Engineering Journal, 2009, 150, 122-130.

53-N. Nasuha, B.H. Hameed, adsorption of methylene blue from aqueous solution onto $\mathrm{NaOH}$-modified rejected tea, Chemical Engineering Journal, 2011, 166, 783-786. 